\title{
Transcriptional regulation of haematopoietic transcription factors
}

\author{
Nicola K Wilson, Fernando J Calero-Nieto, Rita Ferreira and Berthold Göttgens*
}

\begin{abstract}
The control of differential gene expression is central to all metazoan biology. Haematopoiesis represents one of the best understood developmental systems where multipotent blood stem cells give rise to a range of phenotypically distinct mature cell types, all characterised by their own distinctive gene expression profiles. Small combinations of lineage-determining transcription factors drive the development of specific mature lineages from multipotent precursors. Given their powerful regulatory nature, it is imperative that the expression of these lineage-determining transcription factors is under tight control, a fact underlined by the observation that their misexpression commonly leads to the development of leukaemia. Here we review recent studies on the transcriptional control of key haematopoietic transcription factors, which demonstrate that gene loci contain multiple modular regulatory regions within which specific regulatory codes can be identified, that some modular elements cooperate to mediate appropriate tissuespecific expression, and that long-range approaches will be necessary to capture all relevant regulatory elements. We also explore how changes in technology will impact on this area of research in the future.
\end{abstract}

Haematopoiesis represents one of the best studied models of adult stem cell development and differentiation $[1,2]$. Powerful techniques allow purification and in vitro as well as in vivo functional assays of small subsets of cells, from haematopoietic stem cells (HSCs) via a plethora of intermediate progenitors to fully mature cell types. Transcription factors (TFs) directly regulate gene expression and thus control cellular phenotypes. It is no surprise, therefore, that TFs have emerged as some of the most powerful regulators of both normal development and disease.

*Correspondence: bg200@cam.ac.uk

University of Cambridge Department of Haematology, Cambridge Institute for Medical Research, Hills Road, Cambridge, CB2 OXY, UK
TFs play important roles during haematopoiesis, from stem cell maintenance to lineage commitment and differentiation. However, relatively little is known about the way in which regulatory information is encoded in the genome, and how individual TFs are integrated into wider regulatory networks. Based on the recent analysis of large-scale efforts to reconstruct tissue-specific regulatory networks, it has been suggested that transcriptional regulatory networks are characterised by a high degree of connectivity between TFs and transcriptional cofactors. Extensive cross- and autoregulatory links therefore create densely connected regulatory circuits that control the large numbers of tissue-specific effector proteins (enzymes, structural proteins) [3,4] (Figure 1). To understand the functionality of large mammalian regulatory networks, it will therefore be important to identify downstream target genes of specific TFs as well as gain insight into combinatorial TF interactions. This in turn will not only provide fundamental insights into normal development, but also advance our understanding of how deregulation of networks contributes to pathology.

The cis-regulatory regions of a gene locus can be thought of as different modules, each partaking in an important role, such as driving expression of the gene to a specific subset of cells or a specific tissue type. The activity of each regulatory region is controlled by a distinct set of upstream regulators. The individual regulatory regions within a given gene locus may have overlapping or very distinct upstream regulators, and it is the combined activity of all these regions that ultimately controls gene expression. Comprehensive identification and characterisation of true functional cis-regulatory regions therefore represent an essential prerequisite to integrate important regulatory genes into wider transcriptional networks. Traditionally, DNaseI mapping was performed to identify regions of open/accessible chromatin. More recently, comparative genomic sequence analysis has been used to identify highly conserved sequences, which were taken to represent candidate regulatory elements based on the premise that sequence conservation indicated an important function [5-7]. The most recent development has been that of whole genome re-sequencing, which when coupled with chromatin 


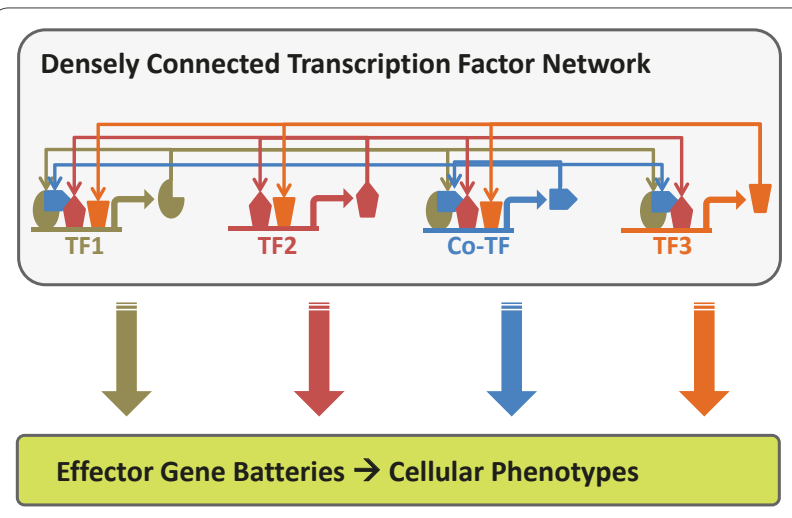

Figure 1. Transcription factor networks control cellular phenotypes. Transcription factors (TFs) together with cofactors (Co-TF) form densely connected regulatory networks that define cellular phenotypes by regulating large numbers of effector genes coding for cell-type-specific structural proteins and enzymes.

immunoprecipitation assays allows genome-wide mapping of the chromatin status for a given histone modification [8]. Though more predictive than previous approaches, these techniques still require functional validation of candidate elements, which involves in vivo and in vitro experiments to assess the true function of a given candidate regulatory region.

Several gene loci coding for TFs essential for haematopoiesis have been characterised using a combination of the above techniques. Collectively, these studies provided important insights into TF hierarchies and regulatory network core circuits [9-11]. This review will specifically focus on three haematopoietic loci, encoding the key haematopoietic regulators Scl/Tal1, Lmo2 and Gfi1.

\section{Transcriptional regulation of $\mathrm{Scl}$}

The basic helix-loop-helix TF Scl/Tal1 is a key regulator of haematopoiesis with additional important roles in the development of the vascular and central nervous systems [12-16]. Within the haematopoietic system, Scl is essential for the development of HSCs as well as further differentiation into the erythroid and megakaryocytic lineages [17].

Since correct spatio-temporal expression of Scl is crucial for the appropriate execution of its biological functions, much effort has been invested into understanding how $S \mathrm{Cl}$ is regulated. Using a combination of long-range comparative sequence analysis and both in vitro and in vivo functional analysis, multiple cis-regulatory elements have been identified in the murine $\mathrm{Scl}$ locus, each of which directs expression to a subdomain of endogenous $\mathrm{Scl}$ expression when tested in transgenic mice (Figure 2). Scl has three promoters located in different exons (exons 1a, 1b and exon 4), none of which displayed haematopoietic activity when tested in transgenic mice. A search for additional cis-regulatory elements led to the identification of three haematopoietic enhancers $(-4,+19$ and $+40 \mathrm{~kb})$. The $-4 \mathrm{Scl}$ enhancer, characterized by the presence of five Ets sites, drives expression to endothelium and fetal blood progenitors [18]. The $+19 \mathrm{Scl}$ enhancer was shown to drive expression of $\mathrm{Scl}$ in HSCs, haematopoietic progenitors and endothelial cells [19-21] and critically depended on an Ets/Ets/GATA composite motif shown to be bound in vivo by Elf-1, Fli-1 and Gata2 [22]. Of note, the +19 enhancer was flanked by a nearby hypersensitive site (+18 Scl element), which did not function as an enhancer but contains a mammalian interspersed repeat that is essential for its ability to 'boost' activity of the +19 element [23]. The $+40 \mathrm{Scl}$ enhancer drives expression to erythroid cells $[24,25]$ as well as midbrain and is characterized by the presence of two Gata/E-box motifs. Mutation or deletion of a single one of these motifs leads to a loss of function of the enhancer [24,25].

Taken together, these studies have highlighted the presence of three haematopoietic enhancers within the murine $S c l$ locus, with distinct yet overlapping regulatory codes that contribute to the overall correct spatiotemporal expression of Scl. Interestingly, a recent study comparing the functionality of the mouse $\mathrm{Scl}$ enhancers with their corresponding chicken counterparts suggested that elements shared by mammals and lower vertebrates exhibit functional differences and binding site turnover between widely separated cis-regulatory modules [26]. Remarkably, however, the regulatory inputs and overall expression patterns remain the same across different species. This in turn suggested that significant regulatory changes may be widespread, and not only apply to genes with altered expression patterns, but also to those where expression is highly conserved.

\section{Transcriptional regulation of $\mathrm{Lmo2}$}

The Lim domain only 2 gene (Lmo2) encodes a transcriptional cofactor that is essential for haematopoiesis $[27,28]$. The Lmo2 protein does not bind to DNA directly but rather participates in the formation of multipartite DNA-binding complexes with other TFs, such as Ldb1, $\mathrm{Scl} /$ Tal1, E2A and Gata1 or Gata2 [29-31]. Lmo2 is widely expressed across haematopoiesis with the exception of mature T-lymphoid cells where aberrant expression of Lmo2 results in T-cell leukaemias [32].

Lmo 2 contains three promoters: the proximal promoter, which drives the majority of expression in endothelial cells [33]; the distal promoter, which is active in the fetal liver and specific T-cell acute lymphoblastic leukemia (T-ALL) cell lines [34]; and the intermediate promoter, which was detected in CD34+ cells and was implicated in mediating LMO2 expression in T-ALL patients where high levels of LMO2 were present in the absence of any 


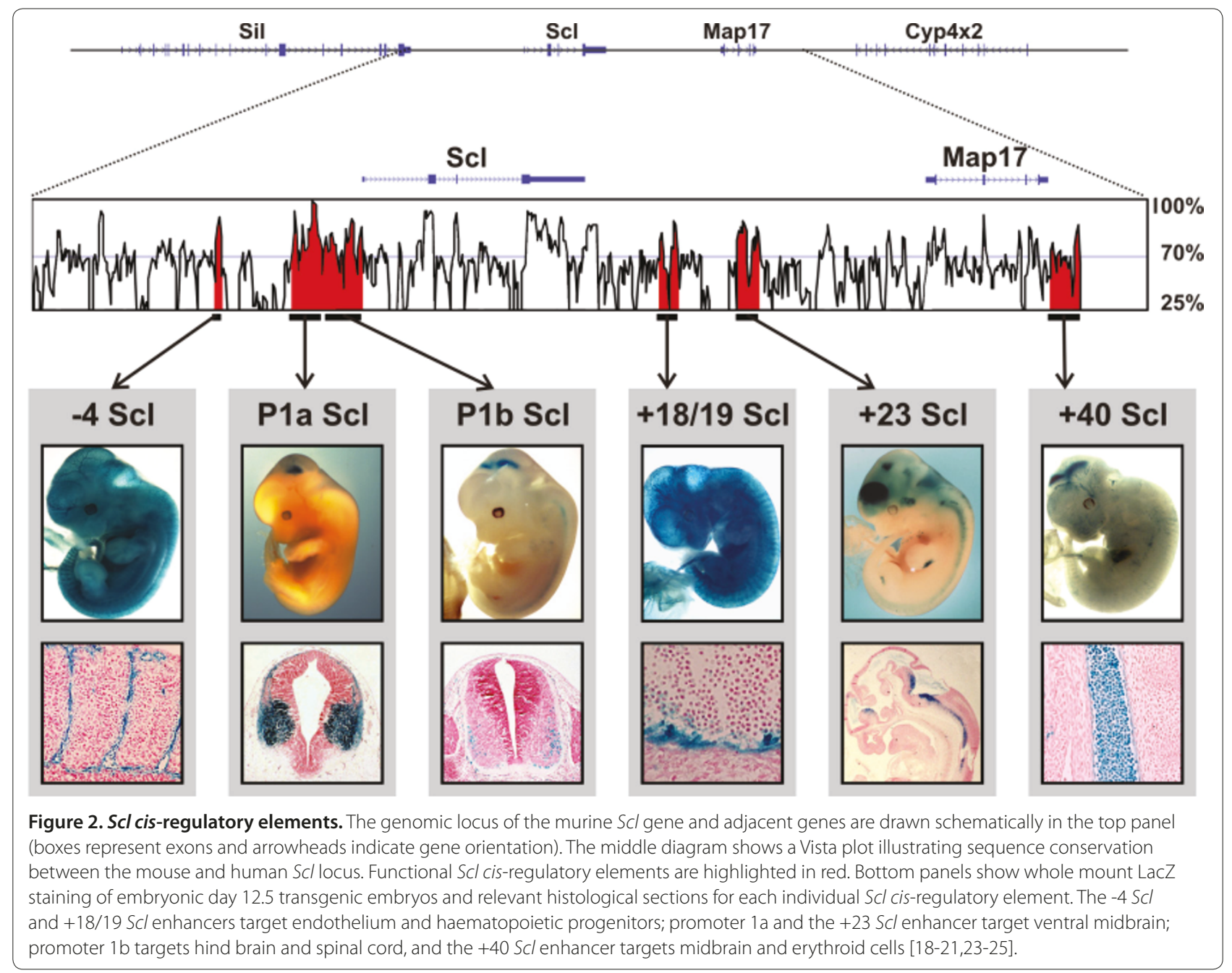

translocation involving the LMO2 locus [35]. However, none of the three promoters on their own displayed robust expression when tested in transgenic mice [33,36], which led to the identification of eight enhancer elements dispersed over $100 \mathrm{~kb}$ that could recapitulate the expression of Lmo2 in normal haematopoiesis [36]. Of note, while individual elements augmented endothelial expression of the proximal promoter, robust haematopoietic expression was only observed when they were combined together (Figure 3). This type of combinatorial collaboration between regulatory elements to obtain haematopoietic activity has been seen for other gene loci, such as Endoglin [37], suggesting a process of step-wise and modular activation of the locus during the development of blood and endothelial cells from their common precursor.

\section{Transcriptional regulation of Gfi1}

The Growth factor independence 1 gene (Gfil) was originally identified in a retroviral screen designed to identify regulatory pathways that could initiate interleukin-2 independence in T cells [38]. Within the haematopoietic system Gfil is expressed in HSCs [39], specific subsets of $\mathrm{T}$ cells [40], granulocytes, monocytes, and activated macrophages [41]. Gfi $1^{-/}$mice lack neutrophils [41,42] and $\mathrm{G} f \mathrm{1}^{-1-} \mathrm{HSCs}$ are unable to maintain long-term haematopoiesis because elevated levels of proliferation lead to eventual exhaustion of the stem cell pool $[39,43]$. Outside the haematopoietic system, Gfil is also specifically expressed in sensory epithelia, the lungs, neuronal precursors, the inner ear, intestinal epithelia and during mammary gland development [44-47].

A recent study used a combination of comparative genomics, locus-wide chromatin immunoprecipitation assays and functional validation within cell lines and transgenic animals to identify cis-regulatory regions within the Gfi1 locus [48]. Four regulatory regions ($3.4 \mathrm{~kb}$ min pro, $-1.2 \mathrm{~kb}$ min pro, $+5.8 \mathrm{~kb}$ enhancer and $+35 \mathrm{~kb}$ enhancer) were shown to recapitulate endogenous expression patterns of Gfil in the central nervous system, 


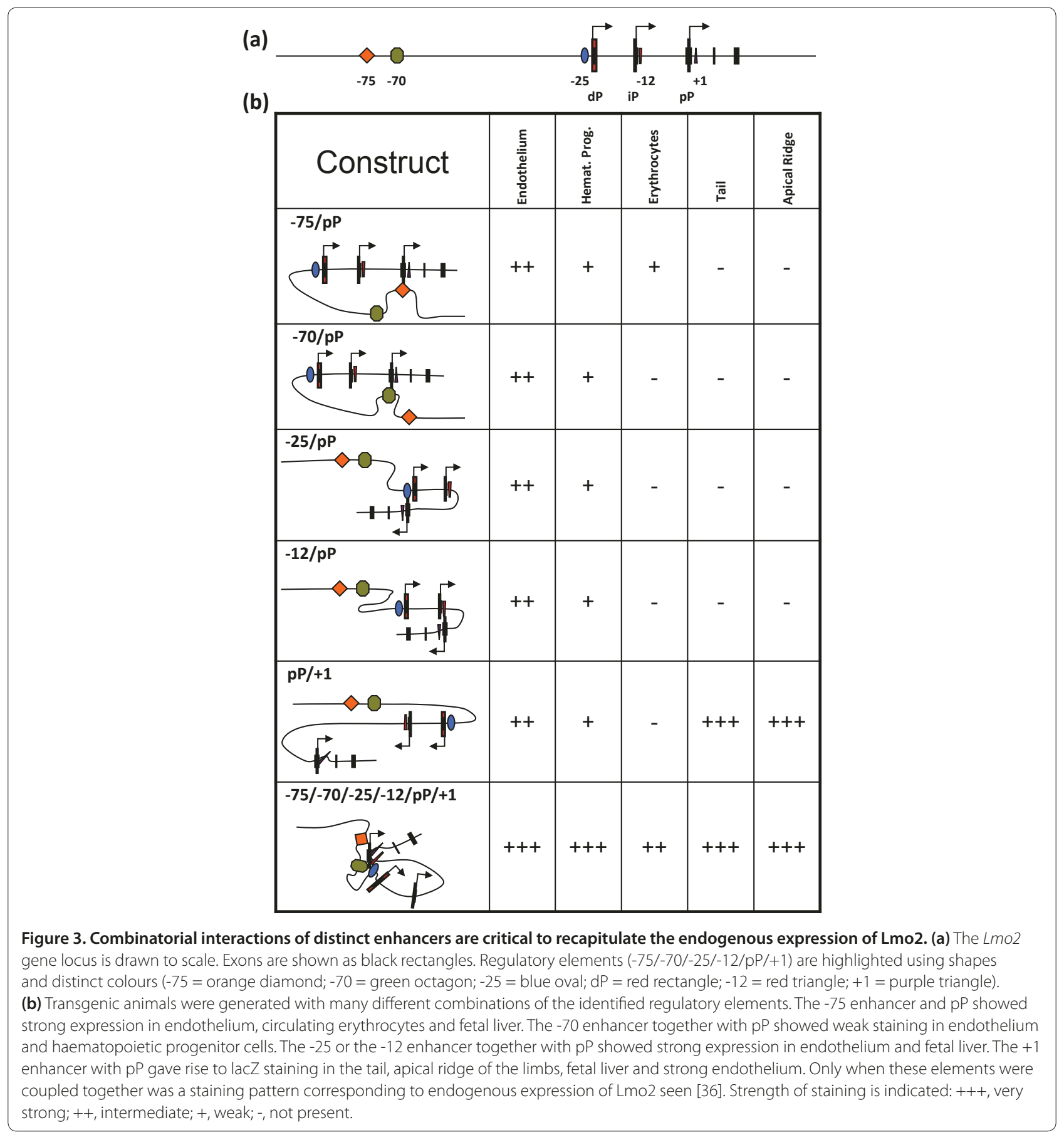

gut, limbs and developing mammary glands but no haematopoietic staining was observed. However, a recent genome-wide ChIP-Seq experiment [49] revealed binding of Scl/Tal1 to a region situated $35 \mathrm{~kb}$ upstream of the Gfi1 promoter within the last intron of its 5' flanking gene, Evi5. This element was subsequently validated in transgenic assays, which demonstrated lacz staining at multiple sites of haematopoietic stem/progenitor cell emergence (vitelline vessels, fetal liver, and dorsal aorta).
Moreover, the element was also shown to be bound by TFs known to be critical for haematopoiesis, including Scl/Tal1, Pu.1/Sfpi1, Runx1, Erg, Meis1, and Gata2, thus integrating Gfi1 into the wider HSC regulatory network. This study therefore supports the notion that important regulatory elements can be located at a significant distance from the gene they control (Figure 4), and thus emphasize the need for careful interpretation of genomewide TF binding datasets $[49,50]$. 


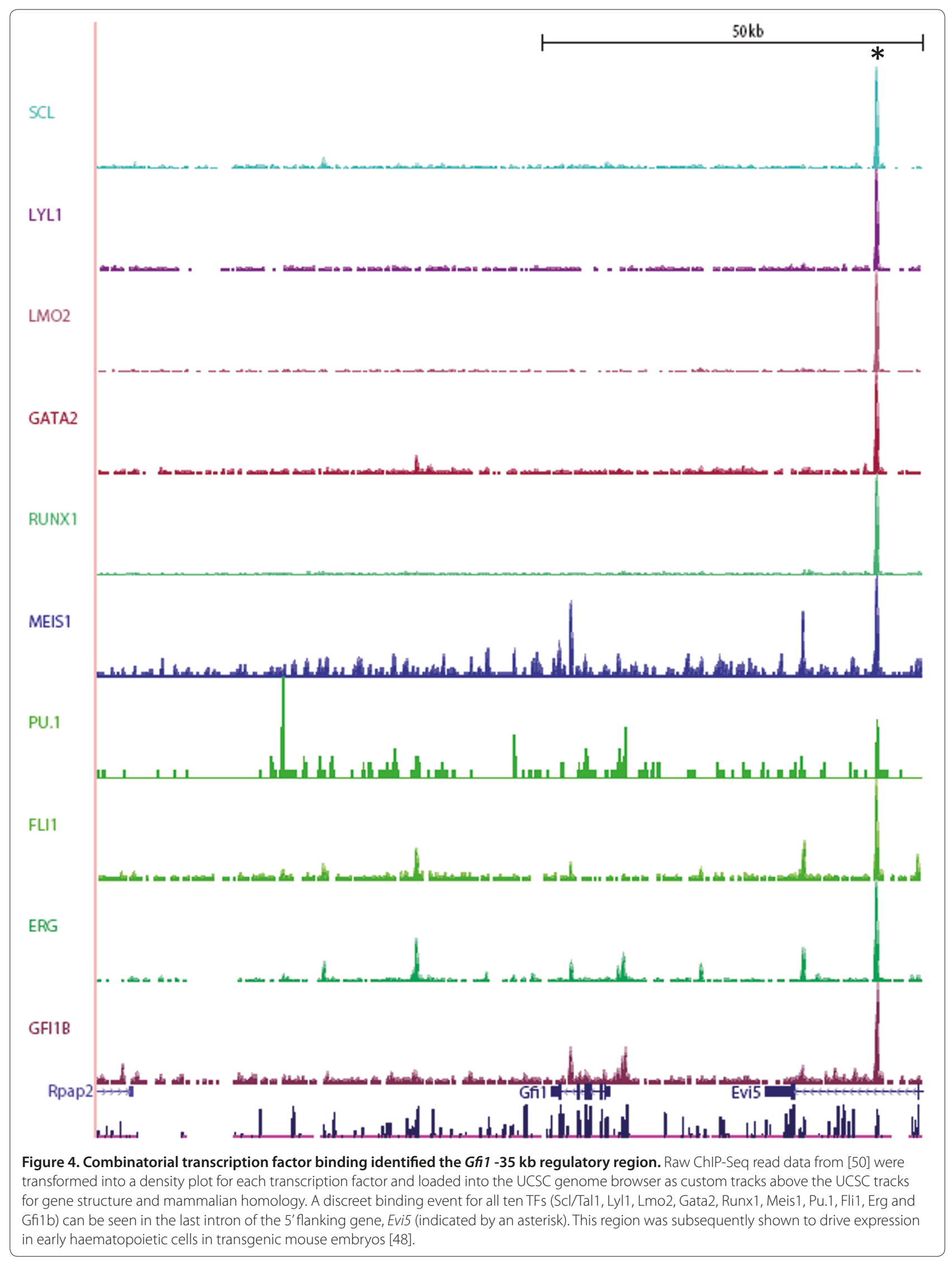




\section{Transcriptional regulation of other key haematopoietic transcription factors}

The transcriptional control of several other TFs known to play important roles within haematopoiesis have also been investigated. Runx1 has been shown to be transcribed from two promoter elements, both of which collaborate with the Runx1 $+23 \mathrm{~kb}$ enhancer to drive expression of Runx1 to sites of HSC emergence [51-53]. Moreover, the Runx1 $+23 \mathrm{~kb}$ region was shown to be regulated by important haematopoietic TFs (Gata2, Fli1, Elf1, Pu.1, Scl, Lmo2, Ldb1 and Runx1 itself) [53,54]. Lyl1 is known to contain a promoter region that can be divided into two separate promoter elements that are responsible for driving the expression of Lyll within endothelial, haematopoietic progenitor, and megakaryocytic cells [55]. These promoter elements were shown to contain conserved Ets and Gata motifs that were bound in vivo by Fli1, Elf1, Erg, Pu.1, and Gata2. Multiple elements within the Gata2 locus have been identified $(-77 \mathrm{~kb},-3.9 \mathrm{~kb},-3 \mathrm{~kb},-2.8 \mathrm{~kb},-1.8 \mathrm{~kb},+9.5 \mathrm{~kb}$ and $1 \mathrm{~s}$ promoter) [56-58] with the $-1.8 \mathrm{~kb}$ region being essential for maintaining Gata2 repression in terminally differentiating cells [58]. Elf1 contains four promoter elements (-55 kb, $-49 \mathrm{~kb},-21 \mathrm{~kb}$ and proximal), which are used in a cell-type-specific manner in combination with a lineagespecific - 14 kb enhancer element [59]. Enhancer elements utilising the Ets/Ets/Gata regulatory code, originally defined in the $S c l+19$ enhancer, were also identified in the Fli1, Gata2, Hhex/Prh and Smad6 gene loci [5,57]. The picture emerging, therefore, is that transcriptional control of important haematopoietic TF loci is achieved through multiple regulatory elements but the number of upstream regulators may be relatively small. The same binding motifs are repeatedly found, but it is the precise arrangement within a single element as well as the interactions between elements that ultimately control expression.

\section{Conclusion}

Recent analysis of gene regulatory networks controlling pluripotency in embryonic stem cells suggests that a finite number of major combinatorial interactions are critical in controlling cellular phenotypes [60,61]. Identification and subsequent functional characterisation of specific regulatory elements provides a powerful route into deciphering these combinatorial regulatory interactions. Whilst traditional methods of identifying regulatory elements should not be overlooked, it is essential to integrate new genome-wide methods to ensure that regulatory elements outside traditional gene loci boundaries are not overlooked. With the genome-wide mapping of TF binding events now eminently feasible, the importance of sequence conservation as a primary technique for identification of regulatory elements will diminish.
This article is part of a review series on Epigenetics and regulation. Other articles in the series can be found online at http://stemcellres. $\mathrm{com} / \mathrm{series} /$ epigenetics

Nevertheless, genome-wide mapping of binding events is descriptive and therefore no substitute for conventional functional assays, which are therefore likely to remain an important component of any research programme aimed at elucidating transcriptional control mechanisms.

\section{Abbreviations}

ChIP-Seq, chromatin immunoprecipitation coupled with whole genome resequencing; HSC, haematopoietic stem cell; T-ALL, T-cell acute lymphoblastic leukemia; $\mathrm{TF}$, transcription factor.

\section{Competing interests}

The authors declare that they have no competing financial interests.

\section{Acknowledgements}

Work in the authors'laboratories is supported by Leukaemia and Lymphoma Research, the Leukaemia and Lymphoma Foundation and the UK Medical Research Council.

Published: 10 February 2011

\section{References}

1. Orkin SH, Zon LI: SnapShot: hematopoiesis. Cell 2008, 132:712.

2. Ottersbach K, Smith A, Wood A, Gottgens B: Ontogeny of haematopoiesis: recent advances and open questions. Br J Haematol 2010, 148:343-355.

3. Davidson $\mathrm{EH}$ : Emerging properties of animal gene regulatory networks. Nature 2010, 468:911-920.

4. modENCODE Consortium, Roy S, Ernst J, Kharchenko PV, Kheradpour P, Negre $\mathrm{N}$, Eaton ML, Landolin JM, Bristow CA, Ma L, Lin MF, Washietl S, Arshinoff BI, Ay F, Meyer PE, Robine N, Washington NL, Di Stefano L, Berezikov E, Brown CD, Candeias R, Carlson JW, Carr A, Jungreis I, Marbach D, Sealfon R, Tolstorukov MY, Will S, Alekseyenko AA, Artieri C, et al:. Identification of functional elements and regulatory circuits by Drosophila modENCODE. Science 2010, 330:1787-1797.

5. Donaldson IJ, Chapman M, Kinston S, Landry JR, Knezevic K, Piltz S, Buckley N, Green AR, Gottgens B: Genome-wide identification of cis-regulatory sequences controlling blood and endothelial development. Hum Mol Genet 2005, 14:595-601.

6. Göttgens B, Barton LM, Gilbert JG, Bench AJ, Sanchez MJ, Bahn S, Mistry S, Grafham D, McMurray A, Vaudin M, Amaya E, Bentley DR, Green AR, Sinclair AM: Analysis of vertebrate SCL loci identifies conserved enhancers. Nat Biotechnol 2000, 18:181-186.

7. Loots GG, Locksley RM, Blankespoor CM, Wang ZE, Miller W, Rubin EM, Frazer KA: Identification of a coordinate regulator of interleukins 4,13 , and 5 by cross-species sequence comparisons. Science 2000, 288:136-140.

8. Barski A, Cuddapah S, Cui K, Roh TY, Schones DE, Wang Z, Wei G, Chepelev I, Zhao K: High-resolution profiling of histone methylations in the human genome. Cell 2007, 129:823-837.

9. Foster SD, Oram SH, Wilson NK, Gottgens B: From genes to cells to tissues - modelling the haematopoietic system. Mol Biosyst 2009, 5:1413-1420.

10. Miranda-Saavedra D, Gottgens B: Transcriptional regulatory networks in haematopoiesis. Curr Opin Genet Dev 2008, 18:530-535.

11. Pimanda JE, Gottgens B: Gene regulatory networks governing haematopoietic stem cell development and identity. Int J Dev Biol 2010, 54:1201-1211.

12. Kallianpur AR, Jordan JE, Brandt SJ: The SCL/TAL-1 gene is expressed in progenitors of both the hematopoietic and vascular systems during embryogenesis. Blood 1994, 83:1200-1208.

13. Muroyama Y, Fujiwara Y, Orkin SH, Rowitch DH: Specification of astrocytes by bHLH protein $\mathrm{SCL}$ in a restricted region of the neural tube. Nature 2005, 438:360-363.

14. Visvader JE, Fujiwara Y, Orkin SH: Unsuspected role for the T-cell leukemia protein SCL/tal-1 in vascular development. Genes Dev 1998, 12:473-479. 
15. Robb L, Lyons I, Li R, Hartley L, Kontgen F, Harvey RP, Metcalf D, Begley CG: Absence of yolk sac hematopoiesis from mice with a targeted disruption of the scl gene. Proc Natl Acad Sci U S A 1995, 92:7075-7079.

16. Shivdasani RA, Mayer EL, Orkin SH: Absence of blood formation in mice lacking the T-cell leukaemia oncoprotein tal-1/SCL. Nature 1995, 373:432-434.

17. Hall MA, Curtis DJ, Metcalf D, Elefanty AG, Sourris K, Robb L, Gothert JR, Jane SM, Begley CG: The critical regulator of embryonic hematopoiesis, SCL, is vital in the adult for megakaryopoiesis, erythropoiesis, and lineage choice in CFU-S12. Proc Natl Acad Sci U S A 2003, 100:992-997.

18. Göttgens B, Broccardo C, Sanchez MJ, Deveaux S, Murphy G, Göthert JR, Kotsopoulou E, Kinston S, Delaney L, Piltz S, Barton LM, Knezevic K, Erber WN, Begley CG, Frampton J, Green AR: The scl +18/19 stem cell enhancer is not required for hematopoiesis: identification of a $5^{\prime}$ bifunctional hematopoietic-endothelial enhancer bound by Fli-1 and Elf-1. Mol Cell Biol 2004, 24:1870-1883

19. Sanchez MJ, Bockamp EO, Miller J, Gambardella L, Green AR: Selective rescue of early haematopoietic progenitors in Scl(-/-) mice by expressing Scl under the control of a stem cell enhancer. Development 2001, 128:4815-4827.

20. Sanchez M, Gottgens B, Sinclair AM, Stanley M, Begley CG, Hunter S, Green AR: An SCL 3' enhancer targets developing endothelium together with embryonic and adult haematopoietic progenitors. Development 1999, 126:3891-3904.

21. Silberstein L, Sanchez MJ, Socolovsky M, Liu Y, Hoffman G, Kinston S, Piltz S, Bowen M, Gambardella L, Green AR, Gottgens B: Transgenic analysis of the stem cell leukemia +19 stem cell enhancer in adult and embryonic hematopoietic and endothelial cells. Stem Cells 2005, 23:1378-1388.

22. Gottgens B, Nastos A, Kinston S, Piltz S, Delabesse EC, Stanley M, Sanchez MJ, Ciau-Uitz A, Patient R, Green AR: Establishing the transcriptional programme for blood: the $\mathrm{SCL}$ stem cell enhancer is regulated by a multiprotein complex containing Ets and GATA factors. EMBO J 2002, 21:3039-3050.

23. Smith AM, Sanchez MJ, Follows GA, Kinston S, Donaldson IJ, Green AR, Gottgens B: A novel mode of enhancer evolution: the Tal1 stem cell enhancer recruited a MIR element to specifically boost its activity. Genome Res 2008, 18:1422-1432.

24. Ogilvy S, Ferreira R, Piltz SG, Bowen JM, Gottgens B, Green AR: The SCL +40 enhancer targets the midbrain together with primitive and definitive hematopoiesis and is regulated by SCL and GATA proteins. Mol Cell Biol 2007, 27:7206-7219.

25. Delabesse E, Ogilvy S, Chapman MA, Piltz SG, Gottgens B, Green AR: Transcriptional regulation of the SCL locus: identification of an enhancer that targets the primitive erythroid lineage in vivo. Mol Cell Biol 2005, 25:5215-5225.

26. Göttgens B, Ferreira R, Sanchez MJ, Ishibashi S, Li J, Spensberger D, Lefevre $P$, Ottersbach K, Chapman M, Kinston S, Knezevic K, Hoogenkamp M, Follows $G$, Bonifer C, Amaya E, Green AR: Cis-regulatory remodeling of the SCL locus during vertebrate evolution. Mol Cell Biol 2010, 30:5741-5751.

27. Yamada Y, Warren AJ, Dobson C, Forster A, Pannell R, Rabbitts TH: The T cell leukemia LIM protein $\mathrm{Lmo} 2$ is necessary for adult mouse hematopoiesis. Proc Natl Acad Sci U S A 1998, 95:3890-3895

28. Warren AJ, Colledge WH, Carlton MB, Evans MJ, Smith AJ, Rabbitts TH: The oncogenic cysteine-rich LIM domain protein rbtn2 is essential for erythroid development. Cell 1994, 78:45-57.

29. Osada H, Grutz G, Axelson H, Forster A, Rabbitts TH: Association of erythroid transcription factors: complexes involving the LIM protein RBTN2 and the zinc-finger protein GATA1. Proc Natl Acad SciU S A 1995, 92:9585-9589.

30. Valge-Archer $V$, Forster A, Rabbitts TH: The LMO1 and LDB1 proteins interact in human $T$ cell acute leukaemia with the chromosomal translocation $\mathrm{t}(11 ; 14)(\mathrm{p} 15 ; \mathrm{q} 11)$. Oncogene 1998, 17:3199-3202.

31. Wadman IA, Osada H, Grutz GG, Agulnick AD, Westphal H, Forster A, Rabbitts $\mathrm{TH}$ : The LIM-only protein Lmo2 is a bridging molecule assembling an erythroid, DNA-binding complex which includes the TAL1, E47, GATA-1 and Ldb1/NLI proteins. EMBO J 1997, 16:3145-3157.

32. Rabbitts TH, Axelson $\mathrm{H}$, Forster A, Grutz G, Lavenir I, Larson $\mathrm{R}$, Osada $\mathrm{H}$, ValgeArcher V, Wadman I, Warren A: Chromosomal translocations and leukaemia: a role for LMO2 in T cell acute leukaemia, in transcription and in erythropoiesis. Leukemia 1997, 11 Suppl 3:271-272.

33. Landry JR, Kinston S, Knezevic K, Donaldson IJ, Green AR, Gottgens B: Fli1, Elf1, and Ets1 regulate the proximal promoter of the LMO2 gene in endothelial cells. Blood 2005, 106:2680-2687

34. Crable SC, Anderson KP: A PAR domain transcription factor is involved in the expression from a hematopoietic-specific promoter for the human LMO2 gene. Blood 2003, 101:4757-4764.

35. Oram SH, Thoms JA, Pridans C, Janes ME, Kinston SJ, Anand S, Landry JR, Lock RB, Jayaraman PS, Huntly BJ, Pimanda JE, Göttgens B: A previously unrecognized promoter of $\mathrm{LMO} 2$ forms part of a transcriptional regulatory circuit mediating LMO2 expression in a subset of T-acute lymphoblastic leukaemia patients. Oncogene 2010, 29:5796-5808.

36. Landry JR, Bonadies N, Kinston S, Knezevic K, Wilson NK, Oram SH, Janes M, Piltz S, Hammett M, Carter J, Hamilton T, Donaldson IJ, Lacaud G, Frampton J, Follows G, Kouskoff V, Göttgens B: Expression of the leukemia oncogene Lmo2 is controlled by an array of tissue-specific elements dispersed over $100 \mathrm{~kb}$ and bound by Tal1/Lmo2, Ets, and Gata factors. Blood 2009, 113:5783-5792.

37. Pimanda JE, Chan WY, Wilson NK, Smith AM, Kinston S, Knezevic K, Janes ME, Landry JR, Kolb-Kokocinski A, Frampton J, Tannahill D, Ottersbach K, Follows GA, Lacaud G, Kouskoff V, Göttgens B: Endoglin expression in blood and endothelium is differentially regulated by modular assembly of the Ets/ Gata hemangioblast code. Blood 2008, 112:4512-4522.

38. Gilks CB, Bear SE, Grimes HL, Tsichlis PN: Progression of interleukin-2 (IL-2)dependent rat $\mathrm{T}$ cell lymphoma lines to IL-2-independent growth following activation of a gene (Gfi-1) encoding a novel zinc finger protein Mol Cell Biol 1993, 13:1759-1768

39. Hock H, Hamblen MJ, Rooke HM, Schindler JW, Saleque S, Fujiwara Y, Orkin SH: Gfi-1 restricts proliferation and preserves functional integrity of haematopoietic stem cells. Nature 2004, 431:1002-1007.

40. Yucel R, Kosan C, Heyd F, Moroy T: Gfi1:green fluorescent protein knock-in mutant reveals differential expression and autoregulation of the growth factor independence 1 (Gfi1) gene during lymphocyte development. J Biol Chem 2004, 279:40906-40917.

41. Karsunky H, Zeng H, Schmidt T, Zevnik B, Kluge R, Schmid KW, Duhrsen U, Moroy T: Inflammatory reactions and severe neutropenia in mice lacking the transcriptional repressor Gfi1. Nat Genet 2002, 30:295-300.

42. Hock H, Hamblen MJ, Rooke HM, Traver D, Bronson RT, Cameron S, Orkin SH: Intrinsic requirement for zinc finger transcription factor Gfi-1 in neutrophil differentiation. Immunity 2003, 18:109-120.

43. Zeng H, Yucel R, Kosan C, Klein-Hitpass L, Moroy T: Transcription factor Gfi1 regulates self-renewal and engraftment of hematopoietic stem cells. EMBO J 2004, 23:4116-4125.

44. Clarkson RW, Wayland MT, Lee J, Freeman T, Watson CJ: Gene expression profiling of mammary gland development reveals putative roles for death receptors and immune mediators in post-lactational regression. Breast Cancer Res 2004, 6:R92-109.

45. Kazanjian A, Wallis D, Au N, Nigam R, Venken KJ, Cagle PT, Dickey BF, Bellen HJ, Gilks CB, Grimes HL: Growth factor independence-1 is expressed in primary human neuroendocrine lung carcinomas and mediates the differentiation of murine pulmonary neuroendocrine cells. Cancer Res 2004, 64:6874-6882.

46. Shroyer NF, Wallis D, Venken KJ, Bellen HJ, Zoghbi HY: Gfi1 functions downstream of Math1 to control intestinal secretory cell subtype allocation and differentiation. Genes Dev 2005, 19:2412-2417.

47. Wallis D, Hamblen M, Zhou Y, Venken KJ, Schumacher A, Grimes HL, Zoghbi $\mathrm{HY}$, Orkin SH, Bellen HJ: The zinc finger transcription factor Gfi1, implicated in lymphomagenesis, is required for inner ear hair cell differentiation and survival. Development 2003, 130:221-232

48. Wilson NK, Timms RT, Kinston SJ, Cheng YH, Oram SH, Landry JR, Mullender J, Ottersbach K, Gottgens B: Gfi1 expression is controlled by five distinct regulatory regions spread over 100 kilobases, with Scl/Tal1, Gata2, PU.1, Erg, Meis 1, and Runx1 acting as upstream regulators in early hematopoietic cells. Mol Cell Biol 2010, 30:3853-3863.

49. Wilson NK, Miranda-Saavedra D, Kinston S, Bonadies N, Foster SD, CaleroNieto F, Dawson MA, Donaldson IJ, Dumon S, Frampton J, Janky R, Sun XH, Teichmann SA, Bannister AJ, Göttgens B: The transcriptional program controlled by the stem cell leukemia gene $\mathrm{Scl} / \mathrm{Tal} 1$ during early embryonic hematopoietic development. Blood 2009, 113:5456-5465.

50. Wilson NK, Foster SD, Wang X, Knezevic K, Schütte J, Kaimakis P, Chilarska PM, Kinston S, Ouwehand WH, Dzierzak E, Pimanda JE, de Bruijn MF, Göttgens B: Combinatorial transcriptional control in blood stem/progenitor cells: genome-wide analysis of ten major transcriptional regulators. Cell Stem Cell 2010, 7:532-544.

51. Bee T, Ashley EL, Bickley SR, Jarratt A, Li PS, Sloane-Stanley J, Gottgens B, de 
Bruijn MF: The mouse Runx $1+23$ hematopoietic stem cell enhancer confers hematopoietic specificity to both Runx1 promoters. Blood 2009,

113:5121-5124

52. Bee T, Liddiard K, Swiers G, Bickley SR, Vink CS, Jarratt A, Hughes JR, Medvinsky A, de Bruijn MF: Alternative Runx1 promoter usage in mouse developmental hematopoiesis. Blood Cells Mol Dis 2009, 43:35-42.

53. Nottingham WT, Jarratt A, Burgess M, Speck CL, Cheng JF, Prabhakar S, Rubin EM, Li PS, Sloane-Stanley J, Kong ASJ, de Bruijn MF: Runx1-mediated hematopoietic stem-cell emergence is controlled by a Gata/Ets/SCLregulated enhancer. Blood 2007, 110:4188-4197.

54. Landry JR, Kinston S, Knezevic K, de Bruijn MF, Wilson N, Nottingham WT, Peitz M, Edenhofer F, Pimanda JE, Ottersbach K, Gottgens B: Runx genes are direct targets of Scl/Tal1 in the yolk sac and fetal liver. Blood 2008, 111:3005-3014

55. Chan WY, Follows GA, Lacaud G, Pimanda JE, Landry JR, Kinston S, Knezevic K, Piltz S, Donaldson IJ, Gambardella L, Sablitzky F, Green AR, KouskoffV, Göttgens B: The paralogous hematopoietic regulators Lyl1 and Scl are coregulated by Ets and GATA factors, but Lyl1 cannot rescue the early Scl-/- phenotype. Blood 2007, 109:1908-1916.

56. Grass JA, Jing H, Kim SI, Martowicz ML, Pal S, Blobel GA, Bresnick EH: Distinct functions of dispersed GATA factor complexes at an endogenous gene locus. Mol Cell Biol 2006, 26:7056-7067.

57. Pimanda JE, Ottersbach K, Knezevic K, Kinston S, Chan WY, Wilson NK, Landry JR, Wood AD, Kolb-Kokocinski A, Green AR, Tannahill D, Lacaud G, Kouskoff V
Göttgens B: Gata2, Fli1, and Scl form a recursively wired gene-regulatory circuit during early hematopoietic development. Proc Natl Acad Sci U S A 2007, 104:17692-17697.

58. Snow JW, Trowbridge JJ, Fujiwara T, Emambokus NE, Grass JA, Orkin SH, Bresnick EH: A single cis element maintains repression of the key developmental regulator Gata2. PLoS Genet 2010, 6:pii:e1001103

59. Calero-Nieto FJ, Wood AD, Wilson NK, Kinston S, Landry JR, Gottgens B: Transcriptional regulation of Elf-1: locus-wide analysis reveals four distinct promoters, a tissue-specific enhancer, control by PU.1 and the importance of Elf-1 downregulation for erythroid maturation. Nucleic Acids Res 2010, 38:6363-6374

60. Chen X, Xu H, Yuan P, Fang F, Huss M, Vega VB, Wong E, Orlov YL, Zhang W, Jiang J, Loh YH, Yeo HC, Yeo ZX, Narang V, Govindarajan KR, Leong B, Shahab A, Ruan Y, Bourque G, Sung WK, Clarke ND, Wei CL, Ng HH: Integration of external signaling pathways with the core transcriptional network in embryonic stem cells. Cell 2008, 133:1 106-1117.

61. Kim J, Chu J, Shen X, Wang J, Orkin SH: An extended transcriptional network for pluripotency of embryonic stem cells. Cell 2008, 132:1049-1061.

\section{doi:10.1186/scrt47}

Cite this article as: Wilson NK, et al:: Transcriptional regulation of

haematopoietic transcription factors. Stem Cell Research \& Therapy 2011, 2:6. 